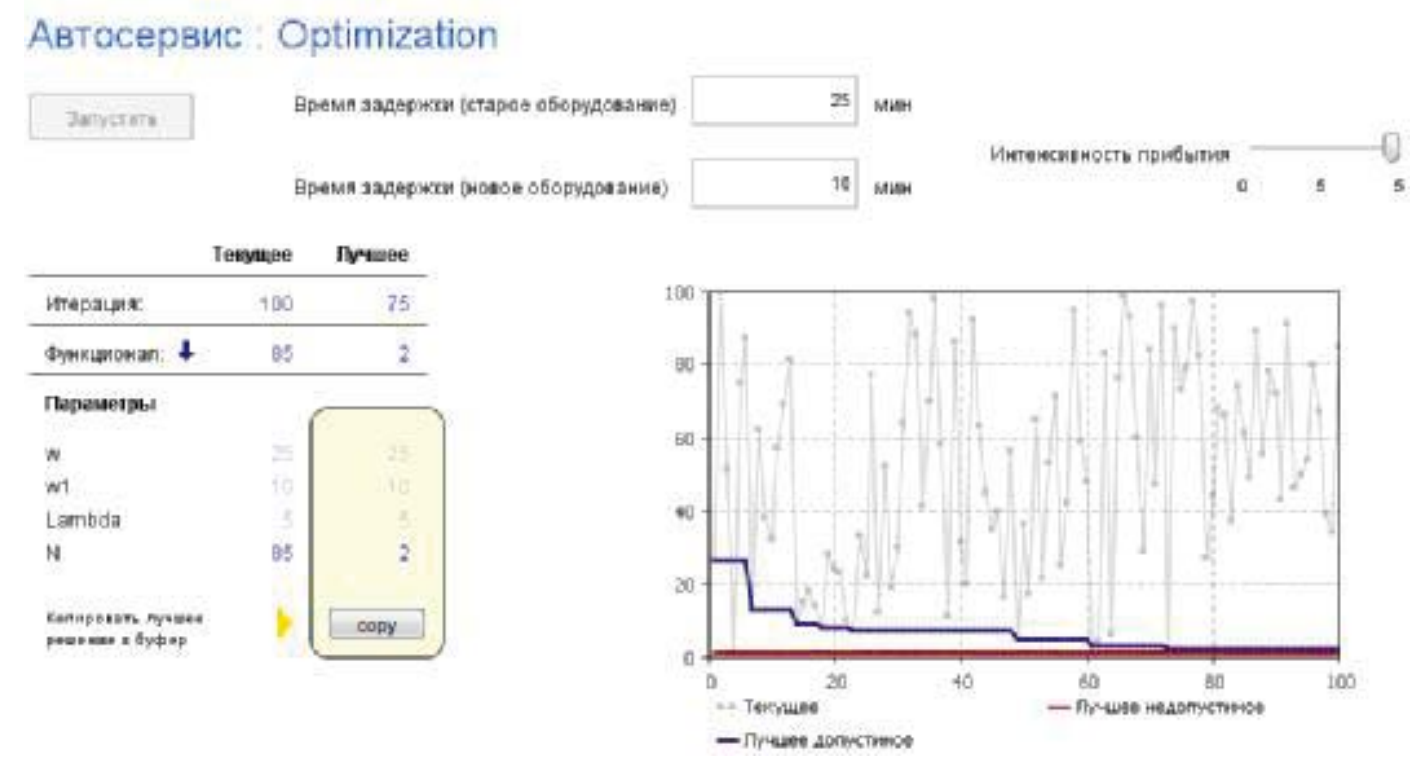

Рис. 5. Эксперимент по оптимизации

Список литературы

1. Куприяшкин,А.Г. Основы моделирования систем: учеб. пособие / А.Г. Куприяшкин; Норильский индустр. ин-т. -Норильск: НИИ, 2015.- С. 13-16.

\title{
Подвижная платформа с пушкой гаусса под управлением Arduino
}

Еремин Д.А., ученик, МОУ Информационно-технологический лицей №24, 2. Нерюнгри

Научные руководители: учитель робототехники Дёминов С.И., педагог дополнительного образования Миколайчук В.А.

Прототипом будущей платформы послужила самая известная на сегодняшний день, устрашающая и не имеющая аналогов на сегодняшний день платформа Армата. Универсальная боевая платформа «Армата»- тяжёлая гусеничная платформа, разработанная Урал вагон заводом. Широкой публике изделия на базе платформы были представлены на параде Победы в 2015 году.

Именно после изучения Универсальной боевой платформы «Армата» пришла в голову идея создания универсальной гусеничной платформы для разработки будущих проектов управляемых роботов. как и в проекте Армата, было решено использовать одну универсальную систему управления которую также можно модернизировать под конкретные задачи будущего робота.

На сегодняшний день существует множество различных способов управления роботами и не всегда есть возможность их использовать. Использование плат Arduino в качестве универсального инструмента управления существенно упрощает создание новых интересных проектов.

Arduino - это электронный конструктор и удобная платформа быстрой разработки электронных устройств для новичков и профессионалов. Платформа 
пользуется огромной популярностью во всем мире благодаря удобству и простоте языка программирования, а также открытой архитектуре и программному коду. Устройство программируется через USB без использования программаторов.

Боевая часть проекта представлена в виде пушки Гаусса

Пушка Гаусса - одна из разновидностей электромагнитного ускорителя масс. Названа по имени немецкого учёного Карла Гаусса, заложившего основы математической теории электромагнетизма.

Цель работы: создать универсальную гусеничную роботизированную платформу с управлением на плате Arduino и пушкой Гаусса на борту.

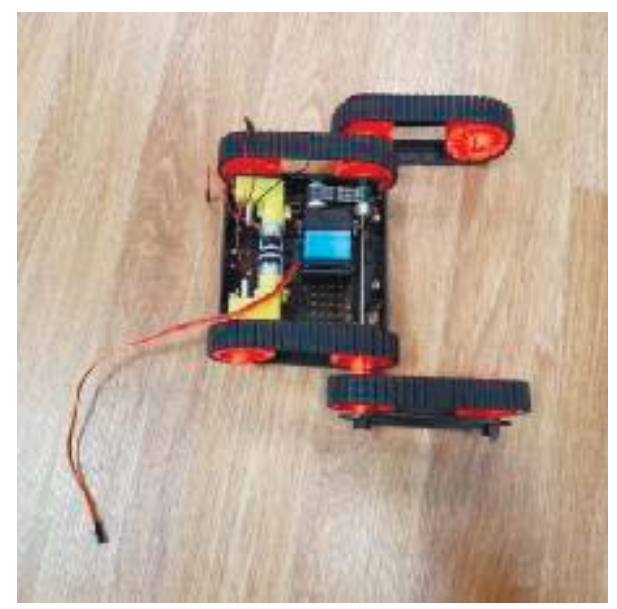

\section{Процесс сборки}

Для начала собираем саму платформу. Для этого устанавливаем 2 двигателя и 1 сервомотор. Закрываем ходовую часть защитной пластиной, предварительно выводим провода двигателей из корпуса, для дальнейшего подключения их к плате управления. Производим установку аккумуляторной батареи на защитную пластину. Устанавливаем 4 стойки, фиксирующие аккумуляторную батарею. Для сборки ствола пушки Гаусса берем трубку от телевизионной антенны длинной 300 мм, диаметром 5 мм. Изолируем место, где будет располагаться катушка. Наматываем на трубку 5 слоев по 35 витков медной проволокой толщиной 0,8 мм. Между слоями используем изоляционную прослойку.

$\begin{array}{rcc}\text { Для } & \text { создания мощного } & \text { кратковременного } \\ \text { импульса } & \text { используем } & \text { высоковольтные }\end{array}$ электролитические конденсаторы, которые припаиваем парами параллельно. Устанавливаем ствол пушки Гаусса и спаянные парами конденсаторы на монтажную плату.

Далее для повышения напряжения и заряда конденсаторов устанавливаем Автомобильный DCAC преобразователь, с заранее напаянными к нему


на вход и выход проводами.

\section{Устанавлива}

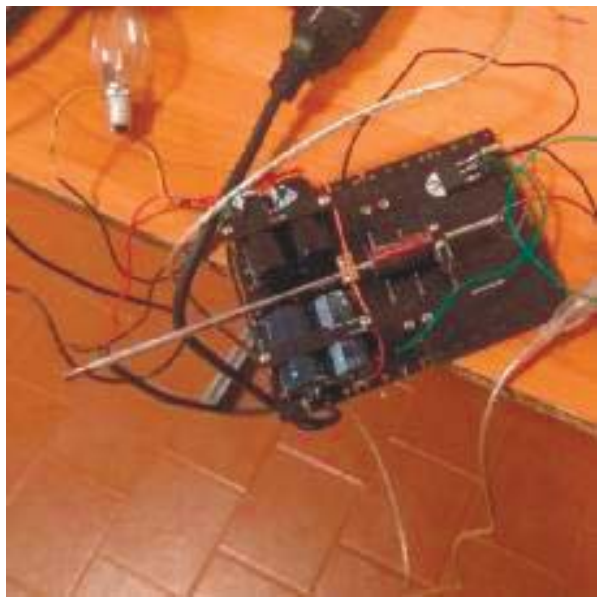

ем плату управления Arduino Uno с платами расширения для подключения двигателей и реле на монтажную плату.

Для подачи снарядов устанавливаем пластиковый контейнер с автоматической системой заряда, представленной в виде сервомотора с толкателем. Данная система позволяет автоматически закладывать снаряды в ствол пушки без прямого участия человека. В качестве способа 
связи оператора с платформой используется Bluetooth. На телефон или планшет устанавливается приложение Bluetooth RC Controller c помощью которого производится управление платформой и пушкой.

В качестве индикации заряда конденсаторов используем лампу накаливания 40Вт. Для разрядки конденсаторов используем реле 250В 12А, управляемое с помощью Arduino (при переключении реле мощный заряд от конденсаторов проходит через соленоид, чем создает магнитное поле внутри катушки, которое разгоняет заряд).

Для обеспечения питания сервомоторов устанавливаем стабилизатор напряжения. На его вход подаем 12В от аккумулятора, на выходе получаем 5B. Далее приступаем к программированию платы управления.

В ходе исследования была изучена техническая литература о существуюих гусеничных платформах, устройстве пушки Гаусса, а также получены навыки работы с платами Arduino. В результате я получил гусеничную платформу, управляемую при помощи Arduino, способную двигаться, преодолевать препятствия и совершать

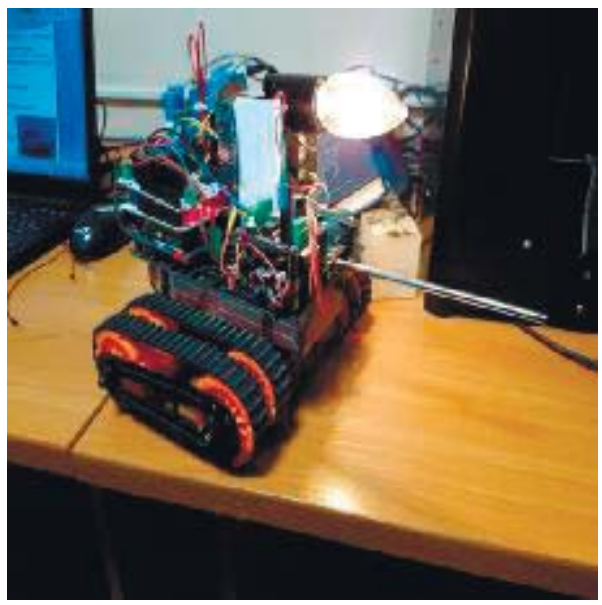
выстрелы с помощью установленной на нее пушки Гаусса.

\section{Список литературы:}

1. http://arduino.ru

2. http://tankbiatlon.ru/tank-t-14-armata/

3. https://ru.wikipedia.org

\section{Мультифункциональная зарядная станция}

Еремин Д.А., ученик, МОУ Информационно-технологический лицей №24, 2. Нерюнгри

Научные руководители: учитель робототехники Дёминов С.И., учитель технологии Коржов И.Н., педагог дополнительного образования Миколайчук В.А.

Под каждый вид аккумулятора требуется отдельное уникальное зарядное устройство и соответственно отдельная розетка, но нет универсального инструмента зарядки, который сочетал бы в себе малые габариты и универсальность зарядки множества устройств. Создание многофункциональной зарядной станции гораздо упростит процедуру заряда аккумуляторов и элементов питания.

Ключевые слова: Многофункциональный, аккумулятор, станция.

Зарядная станция - устройство, предоставляющее электроэнергию для зарядки аккумуляторов и электронных гаджетов, таких как сотовые телефоны и планшеты, аккумуляторы типа АА и т.д. 